\title{
How to Improve the Effect of Live Streaming? From the Perspective of Content Type
}

\author{
Wen-Chin Tsao ${ }^{1}$, Pei-Ching Liao ${ }^{2}$ and Hao-Fan Chumg*
}

\begin{abstract}
With the rapid development of online social media, live streaming has become a global trend and a new direction for strategic marketing in all walks of life. Therefore, this study mainly discusses how to improve audience's attitude toward watching live streaming, and promotes purchase intention and positive word-ofmouth based on the four success factors of live streaming.

The results show that:

1) among the four success factors, only playfulness and interactivity can positively and significantly affect attitude toward watching live streaming;

2) the attitude toward watching has positive and significant impact on the followup behavioural intentions (purchase intention and positive word-of-mouth);

3) the results of moderating analysis show that the positive impact of attitude toward watching on the intention of follow-up behaviour is not significantly different according to different types of live content.

The findings of this study can provide different strategic views on the operation of live streaming platforms for live streaming hosts or those who use the platforms, by which to improve their business performance.
\end{abstract}

Keywords: Live stream platform, Online celebrities, Playfulness, Interactivity, Positive Word-of-Mouth.

\footnotetext{
${ }^{1}$ Professor, Department of Business Administration, National Chin-Yi University of Technology, Taichung, Taiwan, Republic of China.

${ }^{2}$ Postgraduate Student, Department of Business Administration, National Chin-Yi University of Technology, Taichung, Taiwan, Republic of China.

3 Corresponding Author, Assistant Professor, Department of Business Administration, National Chin-Yi University of Technology, Taichung, Taiwan, Republic of China.
} 


\section{Introduction}

According to a behaviour survey of people using broadband networks, as conducted by the Taiwan Network Information Centre (2020), 83.8\% of people aged over 12 have access to the Internet. According to the statistics, the top five mostly used Internet services are real-time communication, online news, audio-visual/live stream, email/searching, and social forums. In addition, it is more and more common for people of Taiwan to engage in online activities with a smartphone, such as shopping, and participating in community and network related application services (wearable devices, online booking, audio-visual services, live broadcast, and mobile payment) (TWNIC, 2020).

The continuous innovation of communication technology and the introduction of 5G will definitely have an impact on the scope of network applications, such as cloud graphic computing, Internet of vehicles, intelligent manufacturing, intelligent energy, wireless medical treatment, wireless family entertainment, networked UAV, social live streaming, personal AI assistant, and smart city. Wang (2016) mentioned that the new audio-visual service of the live stream platform (hereinafter referred to as LSP) is developing rapidly. In addition to maintaining the characteristics of traditional audio-visual sharing platforms, LSPs involve real-time features and interactivity. Through the chat room function, which has also become one of the important features of live streaming, audiences can directly talk with the hosts or other audience members. Chiang (2011) pointed out that most people use social media to share audio-visual advertisements, such as Facebook, which makes the advertisement spread more quickly, and further affects brand image and brand awareness. Relevant reports show that, in addition to social websites, APPs for live streaming have been gradually launched on the Internet (Chen, 2017). Statistics show that more than 560 million people used LSPs in China, accounting for $62 \%$ of the Internet users in the mainland, and such huge business opportunities attract many participants to join the competition. In addition to rewards and filters, live stream marketing by online celebrities has become the most popular business model of E-commerce in the mainland recently.

Nowadays, the influence of social media is everywhere, and celebrities, entertainers, online celebrities, fan groups, and even the general public use live streaming to share their daily life. Besides the live stream function, major social networking websites also own many LSPs, and such popularity indicates the coming era of national live streaming. Together with the encouragement of the online celebrities, live streaming has created a new economic scale (InsightXplorer Ltd., 2017). A review of relevant literature shows that there are many researches related to live steaming, and most of the research topics focus on exploring the success factors of live streaming, the motivation and intention of live streaming, and website loyalty and continuous use intention; however, the impact of the success factors of live streaming on the follow-up use behavior, or the impact of the live streaming content type on the usage behavior, are rarely discussed. Therefore, based on the content types of the live streams, this study attempts to determine the factors conducive to 
the positive attitude of consumers toward watching live streaming, and establishes a mechanism that can strengthen consumers' follow-up behavior (including purchase intention and positive word-of-mouth).

According to the Technology Acceptance Model (TAM) (Davis, 1989), the research model is based on logic thinking of the success factors of live streaming $\rightarrow$ attitude toward watching $\rightarrow$ behavioral intention. In particular, the content type of a live stream is the moderator of this research structure, which was adopted to further test whether the correlation between LSP success factors and the attitude toward watching, and correlation between attitude toward watching and follow-up behavioral intention will change with the content of a live stream. It is intended that this study can provide a reference for the future business strategies of live stream hosts and related participants, gain better audience impressions of the live stream hosts and platforms, further increase the consumption probability, and improve the positive word-of-mouth, which can bring better performance to live stream hosts and enterprises.

\section{Literature Review and Hypotheses Development}

\subsection{Connotations and Success Factors of Live Streaming}

Live streaming has raised a global trend and Facebook is the trend leader of LSPs. Initially, while the live streaming function of Facebook only provided live streaming service to public figures and fan groups labelled with a blue tick, in 2016, live streaming was gradually opened to the general public. Then, Instagram launched the live video function in 2018 in its STORY, which allowed video lengths up to an hour. The Mobile Live streaming of the YouTube App by Google entered the market relatively late. Initially, only YouTubers with more than 10 thousand subscribers were allowed to provide live streaming, which was later changed to 1000 subscribers. After YouTube opened its live streaming, its APP won first place in the App Store download ranking (Chen, 2017).

Lai and Zhang (2016) suggested that the LSP is a combination of many technologies, including online audio-visual service, online video information, social websites, and real-time communication, which gradually developed its unique business model. At present, LSPs have a wide range of global applications, including two-way dialogue between people, live TV programs, and live streaming of various performance activities (such as concerts, sports events, and election campaigns), video games, and even daily life sharing by people (Ou, 2009). Due to its simple operation mode, it is easy to connect and communicate with others synchronously, which enhances the sense of presence for the audiences.

SHOPLINE (2020) divided LSPs into three types, We Media Running (e.g., YouTube, Facebook, and Instagram), Brand Marketing (E-commerce platforms), and Leisure and Recreation (e.g., Twitch, 17 LIVE). According to a survey of the Market Intelligence \& Consulting Institute (MIC) on audiences' preferential choice of LSPs in Taiwan in 2017, it was found that the most selected choice was Facebook (71.6\%), followed by YouTube (55.2\%), 17 LIVE (19.5\%), and Instagram (15.6\%), 
etc. The top five reasons for most audiences to choose LSPs are more free service items, friendly operation interface, diversified program types, diversified interactive methods, and a large number of online celebrities.

The five attractions of Facebook live streaming are:

1) the clear theme makes it easy for audiences to integrate into the situation,

2) asking audiences' opinions, open to questions, relays messages, and response chatting, which can make fans have a sense of involvement, and in turn, increase the good impression and adhesion of the fans to the live stream hosts,

3) advance notice and timely reminders can increase expectations of the fans,

4) hosts are natural but not overly casual,

5) ensures privacy (Wendy, 2016).

According to previous literature, the usefulness, playfulness, interactivity, and incentives are identified as success factors that affect the benefits of LSPs. The following offers a discussion of the leading variables of the four models, respectively.

\subsubsection{Usefulness}

According to the theoretical framework of the TAM of Davis (1989), this study suggests that the perceived usefulness of the LSPs of audiences is significant to the benefits of live streaming. Davis (1989) mentioned that the degree to which people perceive whether a system will help them perform tasks more efficiently will affect their acceptance of the system. Perceived usefulness refers to the actual use of a system or specific information technology, meaning the degree to which people perceive that they can accomplish tasks more efficiently and further raise or improve their work performance (Davis, 1989).

Karahanna and Straub (1999) conducted a study on the usage behavior of email users, and found that the acceptance level of email users will be affected by the level of the perceived helpfulness of the system. Huang (2009) proved that when users perceive high usefulness of a technology system, it will help to improve their positive attitude toward use. Related research has also found that when users use information technology systems, if they feel that they do not need to spend too much effort to learn and can get information to improve some behaviour performance, they tend to give more positive evaluation and judgment of the information technology system (Davis, 1993; Shih, 2004; Bruner II and Kumar, 2005). Therefore, this study inferred that if audiences think that the content and related information provided by the LSPs can help them understand products and implement the purchase decision more efficiently, it will be more conducive to shaping a positive attitude toward watching. Accordingly, this study purposed the following hypothesis:

H1: The perceived usefulness of live streaming has positive correlation with customers' attitude toward watching. 


\subsubsection{Playfulness}

According to Barnett (1990), playfulness is a state of inner pleasure when people participate in activities or use systems. Davis et al. (1992) suggested that playfulness is an important source of intrinsic motivation for people to engage in specific activities, and further defined playfulness as the pleasure and interesting extent a person feels when using a technology information system. Moon and Kim (2001) pointed out that perceived usefulness and ease of use are not sufficient to completely explain the motivation of users; therefore, this study proposes the concept of playfulness to explain the intrinsic motivation of individual behaviour, and defines playfulness as the degree to which an individual feels pleasure from the interactive nature of performing a particular action or activity.

Researchers have indicated that the hedonic or utilitarian value experienced by consumers would trigger the generation of flow (Pelet et al., 2017); therefore, flow is usually applied to the interfaces between humans and computers, as well as other usage interfaces. When the users have flow, they will feel the happiness, incentive, and efficiency of interacting through the interface. The short-term consumption process helps consumers feel happy emotions and inner reactions, which may affect their future consumption behaviour (Tsao and Shao, 2018). Moon and Kim (2001) conducted a study on playfulness, and suggested that playfulness and attitude toward using a network have positive correlation. In addition, the studies of Chin and Gopal (1995) and Davis et al. (1992) showed that playfulness indeed affects attitudes toward consumers' use of technology information systems. In their study of blog use behaviour, Hsu and Lin (2008) found that the higher the perceived playfulness, the higher the positive improvement of attitude toward blog use. Accordingly, this study proposed the following hypothesis:

H2: The playfulness of live streaming has positive correlation with customers' attitude toward watching.

\subsubsection{Interactivity}

Interactivity has been regarded as an important feature of interface design and a critical advantage in communications through computers (Tsao and Yang, 2017). In the past thirty years, interactivity has been widely discussed in various fields, such as advertisement, marketing, communication, information system, and computer science (McMillan and Hwang, 2002). Steuer (1992) proposed that interactivity is "the extent to which users can participate in modifying the format and content of a mediated environment in real time" (Tsao and Yang, 2017). Liu (2003) mentioned that interactivity provides individual subjective control and allows timely and synchronous communication between people.

Previous studies indicated that the higher the perceived interactivity with systems, the more helpful to improve the perceived usefulness. (Tsao and Yang, 2018). According to TAM, it is known that usefulness has positive correlation with the attitude toward use (Davis, 1989); therefore, it is inferred that the higher the users' 
perceived interactivity with a particular technology or system, the more helpful it is to improve the attitude toward use. Hsu (2001) also reported that the higher the positive comments regarding the interactivity of a website, the higher the positive comments on the entire website; that is, more complete interactivity facilitates meeting more user demands, which will be better identified by the users of the websites, and further improve its use. Accordingly, this study proposed the following hypothesis:

H3: The interactivity of live streaming has positive correlation with attitude toward watching.

\subsubsection{Incentive}

The term "incentive" is derived from the Latin verb "movere" which means "to move" (Dhameja and Dhameja, 2009). Incentives can be divided into two types, monetary and non-monetary, and, as such, are a driving force in initiating, guiding and supporting the behaviours of a person or group. Incentives have long been regarded as critical antecedents that affect the behaviour of individuals. For example, reward systems in organisations are highly motivating to employees, encouraging them to complete work tasks or improve their performance (Locke and Latham, 1991; Agba and Ushie, 2010). Lai and Chang (2016) also stated that the provision of a reward or inducement can be used to elicit a desired behaviour in people or to maintain a current behavioural state. Shih and Yang (2011) mentioned that inductive advertising refers to a specific reward or a reward provided by certain incentives which will make consumers respond to the content of an advertisement while Tsao and Mau (2019) claimed that providing monetary and non-monetary incentives for the exchange of consumer comments has become an important marketing strategy in the industry. Monetary incentives include actual cash, raffles, discounts, points that can be redeemed for free products, and partial refunds or rebates while non-monetary incentives involve the provision of free products, services or experiences (Tsao and Mau, 2019). Thus, many marketers have offered raffles or coupons to motivate customers where a coupon can be exchanged for a financial discount or repayment when purchasing a product or service. Customers perceive there is value in an advertisement with incentives.

Noting the literature cited above, it can be inferred that, when viewers watch a live broadcast and perceive that the content of a film offers relevant incentives such as a financial one, it is likely to have a positive impact on their viewing attitude or relevant cognitive judgment of the live broadcast. Therefore, based on prior studies, we propose the following hypothesis:

H4: The incentive of live streaming has positive correlation with attitude toward watching. 


\subsection{Impact of Attitude Toward Watching on Follow-up Behavioral Intention}

Regarding the acceptance studies of information or new technologies, the Theory of Reasoned Action (TRA) and the TAM are the most frequently cited theories. TRA is mainly used to predict or explain the usage behaviour of people; while developed from TRA, TAM is mainly used to study how ordinary people accept or refuse to use new information technology. Therefore, TAM is mainly used to predict or explain the use of information technology and the acceptance level of people (Davis,1989). According to the above theories, it can be inferred that the behaviour of a person is determined by the behavioural intention of the person; while the behavioural intention is determined by the attitude toward the behaviour of the person (Ajzen and Fishbein, 1980; Yang, 2014). Attitude is the judgement of the behaviour of a person whether the implemented behaviour is good or bad, meaning attitude is the positive or negative emotional status toward a particular behaviour (Ajzen \& Fishbein, 1980; Fishbein and Ajzen, 1975).

Taylor and Todd (1995) indicated that use attitude is the subjective feeling of advantage or disadvantage when using a specific information technology or system, and with a positive attitude, the person would be more likely to accept new technology (Demirci, 2009). Usually, the response to the use of a specific system or service is determined by the person's opinion of the system or service; meaning the opinion is closely correlated with perception or viewpoints of using the system or service. Therefore, when individuals think that using a system or service is a good idea, it means that their use will increase; otherwise, if they think that using the system or service is a bad idea, it indicates they will reduce their willingness to use the system or service (Yang, 2014). According to the above literature, it can be inferred that if the audiences have a favourable attitude when watching live streaming, the audiences will increase their willingness to buy the products. Accordingly, this study proposed the following hypothesis:

\section{H5: Attitude toward watching has positive correlation with purchase intention.}

Word-of-mouth (WOM) refers to a person passing information to another through oral communication. Harrison-Walker (2001) defined WOM as "informal, personto-person communication between a perceived non-commercial communicator and a receiver regarding a brand, a product, an organization, or a service." WOM plays an important role in the formation of the attitudes and behaviours of online shoppers. The effect of WOM has been calculated as nine times more effective than advertising in transforming unfavourable or neutral attitudes into positive ones (Day, 1971).

Wirtz and Chew (2002) mentioned that regardless of the motivation sources of the consumers, they hope to gain useful information through other consumer terminals; at the same time, consumers may be willing to provide relevant information or opinions on the products. When consumers feel a certain degree of satisfaction, they 
will have the motivation to provide positive word-of-mouth, and with such increased satisfaction, this motivation can continue to increase, and positive wordof-mouth can be spread. Based on the TAM theory, a positive attitude will have a positive impact on the follow-up behaviour intention of consumers (Davis et al., 1988); therefore, this study suggested that when audiences have a better attitude in the process of watching live streaming, it helps to trigger their intention to spread positive word-of-mouth. Accordingly, this study proposed the following hypothesis:

H6: Attitude toward watching has positive correlation with positive word-of-mouth spreading.

\subsection{Moderating Analysis on Type of Live Streaming \\ 2.3.1 Content Type of Live Streaming}

With the rise of Facebook live auctions, live shopping guides and real-time interactions make online shopping more convenient, and live sales have become a new marketing strategy and scheme. Live content can be divided into the following two types:

\section{Demonstration teaching}

The content of demonstration teaching has the following characteristics:

a) The demonstrator shows the target behaviour.

b) Video shooting has its own purpose, specific learners, editing, and postproduction.

c) The length of a video is not long, usually from three seconds to one or two minutes.

d) After watching a video, the learners can immediately practice the target behaviour demonstrated in the video.

e) Only correct behaviours are demonstrated (Wang, 2016).

Therefore, this study defined demonstration teaching as the hosts independently completing the target behaviour in a live stream, while the audiences watch the teaching content and learn the specific behaviour.

\section{Selling product}

Live content in the form of selling products refers to celebrity endorsements, where the attributes, features, functions, or benefits of the products are introduced, which are intended to achieve the effect of word-of-mouth spreading and persuasion. Many consumers buy products due to the recognition and recommendation of celebrities (Kamins, 1990; Peterson and Kerin, 1977). Therefore, this study suggested that the content type of selling a product means it is endorsed by the live streaming hosts, and the attributes, features, or functions of specific products are introduced, which are intended to affect consumers attitudes toward the products and their follow-up purchase decisions. Endorsement is to use the popularity of a live streaming host to help the enterprise strengthen its brand and product image, and then, promote commodity sales (Brooks and Harris, 1998). 


\subsubsection{Hypothesis Inference}

As "I want to buy" moments increasingly become "I want to watch" moments, the majority of brands or sellers are improving their video strategies by designing the inclusion of useful content (Mooney and Johnsmeyer, 2015). Likewise, with the prevalence of video-sharing websites, increasing numbers of haul videos have been widely seen to offer teaching demonstrations and these have different effects on customers' shopping intentions (Jeffries, 2011). This is mainly because what customers watch and when they watch will influence their willingness to buy products. The teaching demonstrations of video haulers provide a new way for viewers to research products before buying. The experience of watching a video can be combined with shopping behaviour in order to facilitate shoppers in making decisions and allowing them to comprehend more clearly which products are best for them (Sykes and Zimmerman, 2014).

From the perspective of experiential marketing, manufacturers should convey product features and benefits, and link products with unique and interesting consumer experiences. Marketing commentators describe experiential marketing as not selling goods, but showing how brands enrich the lives of consumers (Keller \& Swaminathan, 2020). Taking a demonstration teaching video of cosmetics as an example, the live stream hosts show the existing products, demonstrate the steps and skills to apply the makeup, and introduce the basic attributes and benefits of the colors of the cosmetic products, which makes the consumers feel as if they are performing the make-up actions of the video; therefore, compared with other ways of selling products, the interactive teaching process of the hosts is more helpful to improve consumers' experience of the five dimensions, namely, sense, feel, think, act, and relate (Schmitt, 1999). Inferred from the above documents, this study suggests that the positive impact of the attitude toward watching on the follow-up behavior (purchase intention and word-of-mouth spreading) will change with the content of the live stream, and especially when the content is demonstration teaching, the positive impact will be increased. Accordingly, this study proposed the following hypotheses:

H7a: In comparison with selling products, the live streaming content of demonstration teaching has more significant positive impact on attitude toward watching and product purchase intention.

H7b: In comparison with selling products, the live streaming content of demonstration teaching has more significant positive impact on attitude toward watching and positive word-of-mouth. 


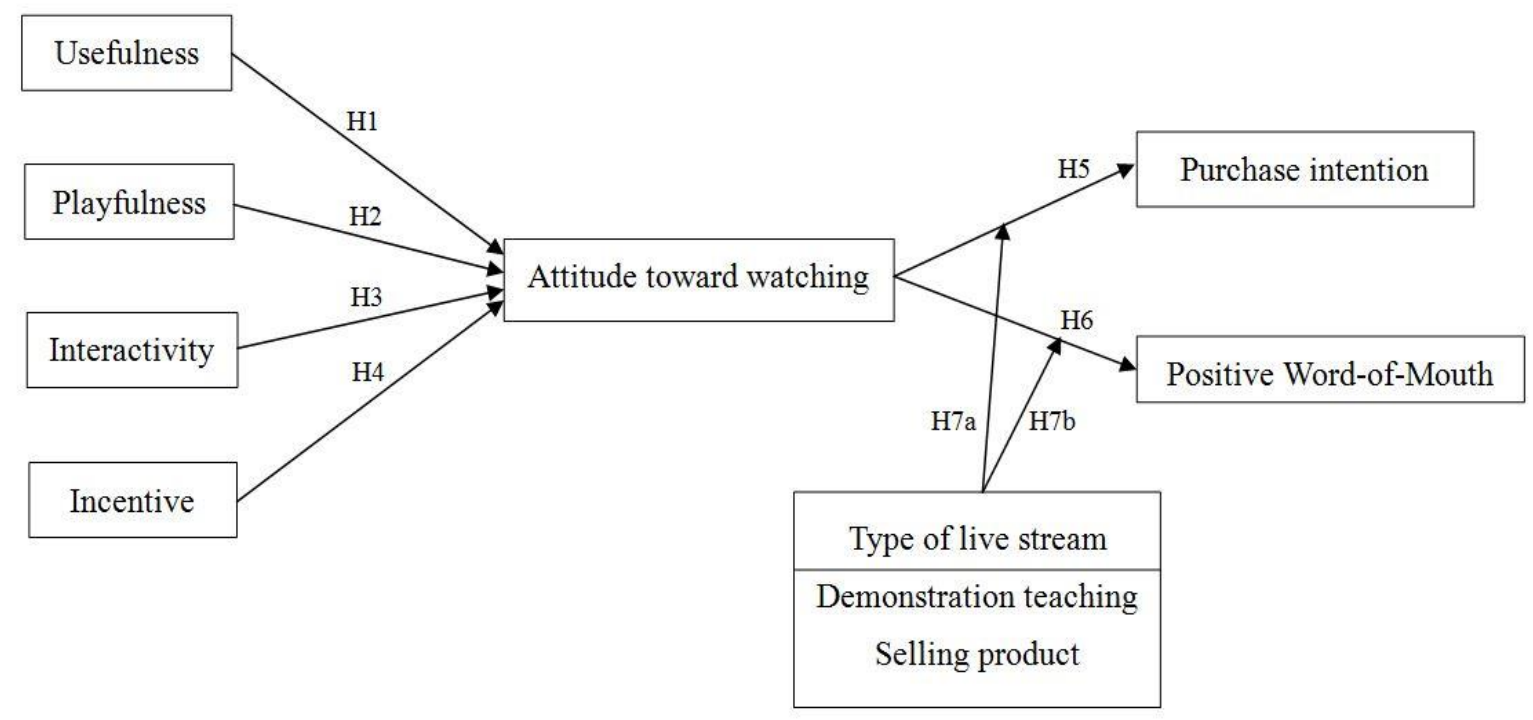

Figure 1: Conceptual model

\section{Methods}

\subsection{Development of Measures}

First, this study put forward definitions of the four success factors of live streaming. According to Davis (1989), usefulness refers to the degree to which a person believes that using a particular system would enhance his or her job performance; therefore, the usefulness of live streaming in this study is defined as the degree to which it helps audiences master and understands the information of products more easily. Playfulness is perceived when implementing specific behaviour or specific activities, meaning the users find that such interaction is interesting in nature (Moon and Kim, 2001). This study defined the playfulness of live streaming as the degree to which audiences feel the passing of time and the inner pleasure. Interactivity provides individual subjective control, and allows timely and synchronous communication between people (Liu, 2003). The interactivity of live streaming in this study is defined as the degree to which the live stream hosts and audiences can conduct two-way, real time, and synchronous communication. Incentive is the internal drive motivating the actor (Locke and Latha, 1990). The incentive of live streaming in this study is defined as, when watching live streaming, the degree to which the audiences would be attracted to the financial reasoning of the video.

Then, this study defined the dependent variables of the three research modes. Attitude refers to an individual's persistent and consistent tendency towards people, things, and the surrounding world. In this study, the attitude toward watching refers to the audiences' stable perception and evaluation tendency toward the relevant audio-visual content of the live stream. Purchase intention is the consumers' tendency to purchase a particular brand or product in the future (Belch and Belch, 
2004). Positive word-of-mouth is the possibility that customers are willing to orally pass on positive information to others (Molinari et al., 2008). There are a total of 36 measurement items among the above seven constructs. Each construct was measured by Likert seven-point scale, from strongly disagree to strongly agree with scores from one to seven, respectively. Question contents and related references are provided in Appendix A.

The moderator in this research model is the content type of live streaming. According to relevant literature, this study divided the live content into two types: demonstration teaching and selling products. In demonstration teaching, the hosts pre-set the target behaviour for the learners, then, through live streaming, teach the audiences to learn the target behaviour step by step. In addition, live streaming with the intent to sell products mainly takes the form of celebrity endorsement, which focuses on the introduction of attributes, features, functions, or benefits, which are intended to persuade or guide the audiences to purchase.

\subsection{Data Collection and Sample Profile}

This study took audiences that have watched live streaming online as the population, considered the accessibility and validity of the sample selection, adopted the convenience sampling method of non-random sampling, and employed social platforms as the sample medium to select the samples to complete the questionnaires. This study hyperlinked four research situations and questionnaire websites on the social platforms of Facebook, questionnaire communication communities, and personal Line communities, and selected two existing LSPs of FB Fan Pages as the test subjects, namely iGift and Spring Vodka. Both of the hosts used demonstration teaching and selling products to guide purchases; therefore, there were a total of four live stream shopping guide situations, which were listed in hyperlinks for the respondents to enter according to their preference. In order to reduce the probability that respondents may choose a hyperlink due to the order, the order of the hyperlinks was changed randomly in an attempt to reduce the deviation of non-random sampling.

In order to improve the validity of the sample, this study set two screening questions to select samples. Respondents must pass the two screening questions to become qualified samples, and the screening questions were:

1) Have you ever watched live streaming? The answer must be yes to be qualified.

2) What kind of shopping guide is the video you just watched? The respondents must identify the right type of live stream to be qualified.

Based on the above criteria, after excluding 87 invalid questionnaires from the collected 281 questionnaires, the number of valid samples was 194, among which, 68 were males $(35.1 \%)$ and 126 were females $(64.9 \%)$. Among the respondents, there were $117(60.3 \%)$ aged from 20 to 30 years old, followed by $40(20.6 \%)$ aged under 20 years old. Regarding education level, there were $132(68 \%)$ respondents with college and university education, followed by 43 (22.2\%) with master's degree. 
In terms of occupation, the number of students accounted for the most with 100 $(51.5 \%)$, followed by $29(14.9 \%)$ in the service industry. The most frequently watched LSP was Facebook, with 85 respondents (43.8\%), followed by YouTube with $54(27.8 \%)$, and Instagram with 40 (20.6\%).

\section{Analysis and Results}

\subsection{Reliability and Validity}

Then CFA was used to verify the unidimensionality of each construct (Anderson and Gerbing, 1988). As illustrated in Table 1, all Cronbach's $\alpha$ estimates were all greater than 0.7 . The figures for composite reliability were all greater than 0.6 , indicating that each construct met the requirement for internal consistency (Nunnally, 1978; Fornell, 1992). As shown in Table 1, the factor standardized loading of the 36 measurement items was between 0.773 and 0.969 . Considering a judgment threshold greater than 0.7 , this indicates that the three constructs are consistent with convergent validity (Hair et al., 2009).

Discriminant validity is assured when the shared variance among any two constructs (i.e., the square of their intercorrelation) is less than the AVE of each construct (Fornell and Larcker, 1981). As shown in Table 2, the AVE of the underlying construct was greater than the shared variance with other construct. This implies that seven constructs exhibited discriminant validity. 
Table 1: Scale items and measured properties

\begin{tabular}{|c|c|c|c|c|c|c|c|c|}
\hline Construct & $\begin{array}{c}\text { Measured } \\
\text { Item }\end{array}$ & Mean & S.D. & $\begin{array}{c}\begin{array}{c}\text { Standardized } \\
\text { loading }\end{array} \\
\end{array}$ & t-value & $\begin{array}{l}\text { Composite } \\
\text { reliability }\end{array}$ & $\begin{array}{c}\begin{array}{c}\text { Cronbach's } \\
\text { alpha }\end{array} \\
\end{array}$ & AVE \\
\hline \multirow{5}{*}{$\begin{array}{l}\text { Usefulness } \\
\text { (UFN) }\end{array}$} & UFN1 & 5.088 & 1.330 & 0.904 & --- & \multirow{5}{*}{0.965} & \multirow{5}{*}{0.954} & \multirow{5}{*}{0.846} \\
\hline & UFN2 & 5.149 & 1.340 & 0.933 & 19.107 & & & \\
\hline & UFN3 & 4.979 & 1.439 & 0.902 & 17.351 & & & \\
\hline & UFN4 & 5.242 & 1.414 & 0.949 & 19.959 & & & \\
\hline & UFN5 & 5.237 & 1.402 & 0.910 & 17.441 & & & \\
\hline \multirow{5}{*}{$\begin{array}{l}\text { Playfulness } \\
\text { (PFN) }\end{array}$} & PFN1 & 4.546 & 1.648 & 0.773 & --- & \multirow{5}{*}{0.925} & \multirow{5}{*}{0.894} & \multirow{5}{*}{0.711} \\
\hline & PFN2 & 3.716 & 1.806 & 0.823 & 9.269 & & & \\
\hline & PFN3 & 4.603 & 1.514 & 0.905 & 10.990 & & & \\
\hline & PFN4 & 4.552 & 1.524 & 0.889 & 10.914 & & & \\
\hline & PFN5 & 4.284 & 1.599 & 0.815 & 9.786 & & & \\
\hline \multirow{6}{*}{$\begin{array}{l}\text { Interactivity } \\
\text { (ITA) }\end{array}$} & ITA1 & 5.021 & 1.472 & 0.846 & --- & \multirow{6}{*}{0.959} & \multirow{6}{*}{0.947} & \multirow{6}{*}{0.794} \\
\hline & ITA2 & 4.696 & 1.501 & 0.860 & 13.212 & & & \\
\hline & ITA3 & 5.160 & 1.388 & 0.917 & 15.090 & & & \\
\hline & ITA4 & 5.098 & 1.318 & 0.931 & 15.797 & & & \\
\hline & ITA5 & 5.119 & 1.332 & 0.897 & 14.557 & & & \\
\hline & ITA6 & 5.067 & 1.389 & 0.893 & 14.452 & & & \\
\hline \multirow{5}{*}{$\begin{array}{l}\text { Incentive } \\
\text { (ICT) }\end{array}$} & ICT1 & 4.886 & 1.497 & 0.925 & --- & \multirow{5}{*}{0.961} & \multirow{5}{*}{0.949} & \multirow{5}{*}{0.832} \\
\hline & ICT2 & 4.887 & 1.506 & 0.936 & 23.701 & & & \\
\hline & ICT3 & 4.804 & 1.565 & 0.925 & 20.931 & & & \\
\hline & ICT4 & 4.825 & 1.657 & 0.880 & 16.316 & & & \\
\hline & ICT5 & 5.129 & 1.553 & 0.893 & 17.472 & & & \\
\hline \multirow{7}{*}{$\begin{array}{c}\text { Attitude } \\
\text { toward } \\
\text { watching } \\
\text { (ATW) }\end{array}$} & ATW1 & 4.376 & 1.751 & 0.931 & --- & \multirow{7}{*}{0.973} & \multirow{7}{*}{0.966} & \multirow{7}{*}{0.839} \\
\hline & ATW2 & 4.521 & 1.639 & 0.946 & 25.403 & & & \\
\hline & ATW3 & 4.433 & 1.586 & 0.918 & 21.871 & & & \\
\hline & ATW4 & 4.794 & 1.361 & 0.900 & 19.532 & & & \\
\hline & ATW5 & 4.273 & 1.636 & 0.913 & 21.043 & & & \\
\hline & ATW6 & 4.706 & 1.716 & 0.866 & 17.463 & & & \\
\hline & ATW7 & 4.469 & 1.476 & 0.934 & 23.218 & & & \\
\hline \multirow{5}{*}{$\begin{array}{c}\text { Purchase } \\
\text { intention } \\
\text { (PI) }\end{array}$} & PI1 & 3.892 & 1.674 & 0.937 & --- & \multirow{5}{*}{0.965} & \multirow{5}{*}{0.954} & \multirow{5}{*}{0.845} \\
\hline & PI2 & 4.064 & 1.658 & 0.929 & 23.323 & & & \\
\hline & PI3 & 3.423 & 1.696 & 0.904 & 19.612 & & & \\
\hline & PI4 & 4.077 & 1.596 & 0.922 & 20.809 & & & \\
\hline & PI5 & 3.964 & 1.639 & 0.903 & 19.117 & & & \\
\hline \multirow{3}{*}{$\begin{array}{l}\text { Positive } \\
\text { Word-of- } \\
\text { Mouth } \\
\text { (PWOM) }\end{array}$} & PWOM1 & 4.170 & 1.721 & 0.964 & --- & \multirow{3}{*}{0.977} & & \\
\hline & PWOM2 & 4.005 & 1.702 & 0.969 & 27.870 & & 0.964 & 0.934 \\
\hline & PWOM3 & 4.129 & 1.679 & 0.966 & 27.546 & & & \\
\hline
\end{tabular}


Table 2: Fornell/Larcker criterion for the seven constructs.

\begin{tabular}{|c|c|c|c|c|c|c|c|}
\hline Construct & UFN & PFN & ITA & ICT & ATW & PI & PWOM \\
\hline UFN & $0.846 \mathrm{a}$ & & & & & & \\
\hline PFN & 0.429 & 0.711 & & & & & \\
\hline ITA & 0.354 & 0.332 & 0.794 & & & & \\
\hline ICT & 0.453 & 0.331 & 0.372 & 0.832 & & & \\
\hline ATW & 0.420 & 0.637 & 0.454 & 0.387 & 0.839 & & \\
\hline PI & 0.370 & 0.425 & 0.259 & 0.475 & 0.430 & 0.845 & \\
\hline PWOM & 0.354 & 0.507 & 0.329 & 0.339 & 0.572 & 0.671 & 0.934 \\
\hline
\end{tabular}

${ }^{a}$ Average variance extracted on diagonal; the square of their intercorrelation below the diagonal.

\subsection{The Fitness of the Structural Model and Hypotheses Tests}

The structural equation modeling (SEM) was applied to estimate the parameters of the structural model shown in Figure 1, and the completely standardized solutions computed by the Amos 21 maximum-likelihood method. As shown in Table 3, the fit measures in the structure model had fit the data reasonably well $(\chi 2(194)=$ 1277.840; d.f. $=582 ; \chi 2$ /d.f. $=2.196 ; \mathrm{CFI}=0.919 ; \mathrm{AGIF}=0.713 ; \mathrm{RMSEA}=0.079)$. With the exception of AGFI (which was slightly low) and RMSEA (which was slightly high), all other indices met the criteria (Bagozzi and Yi, 1988). While scholars generally suggest that the AGFI is higher than 0.9 , other scholars have suggested that the scope could be slightly expanded (Baumgartner and Homburg, 1996). Accordingly, the AGFI of this research model was acceptable. At slightly higher than 0.05, the RMSEA of this model fell within the acceptable range of 0.05 to 0.08 (Browne and Cudeck, 1992).

According to Table 3, among the four leading variables in the model, only playfulness and interactivity had significant positive correlation with attitude toward watching; therefore, $\mathrm{H} 2$ and $\mathrm{H} 3$ are supported. As the correlation of usefulness and incentive with attitude toward watching was not verified as expected, $\mathrm{H} 1$ and $\mathrm{H} 4$ are not supported. Finally, attitude toward watching has significant positive impact on repurchase intention and positive word-of-mouth; therefore, H5 and $\mathrm{H} 6$ are supported. 
Table 3: Structural parameter estimates and goodness-of-fit indices

\begin{tabular}{|c|c|c|c|c|}
\hline Hypothesis & Path & $\begin{array}{c}\text { Standardized } \\
\text { coefficient }\end{array}$ & $\begin{array}{c}t \text {-value } \\
\text { (S.E.) }\end{array}$ & Result \\
\hline $\mathrm{H} 1$ & $\begin{array}{c}\text { Usefulness } \rightarrow \\
\text { Attitude toward } \\
\text { watching }\end{array}$ & -0.022 & $-0.339(0.092)$ & Unsupported \\
\hline $\mathrm{H} 2$ & $\begin{array}{c}\text { Playfulness } \\
\rightarrow \text { Attitude } \\
\text { toward watching }\end{array}$ & $0.671 * * *$ & $8.095(0.121)$ & Supported \\
\hline H3 & $\begin{array}{c}\text { Interactivity } \\
\rightarrow \text { Attitude } \\
\text { toward watching }\end{array}$ & $0.250 * * *$ & $4.316(0.080)$ & Supported \\
\hline $\mathrm{H} 4$ & $\begin{array}{c}\text { Incentive } \\
\rightarrow \text { Attitude } \\
\text { toward watching }\end{array}$ & 0.101 & $1.661(0.072)$ & Unsupported \\
\hline H5 & $\begin{array}{c}\text { Attitude toward } \\
\text { watching } \rightarrow \\
\text { Purchase } \\
\text { intention }\end{array}$ & $0.707 * * *$ & $11.683(0.058)$ & Supported \\
\hline H6 & $\begin{array}{l}\text { Attitude toward } \\
\text { watching } \rightarrow \\
\text { Positive Word- } \\
\text { of-Mouth }\end{array}$ & $0.804 * * *$ & $14.676(0.055)$ & Supported \\
\hline
\end{tabular}

Fit indices: $\chi^{2}{ }_{(194)}=1277.840 ;$ d.f. $=582 ; \chi^{2} /$ d.f. $=2.196 ; \mathrm{AGFI}=0.713 ; \mathrm{CFI}=$ $0.919 ;$ RMSEA $=0.079$.

*p<0.05; ${ }^{* *} p<0.01 ;{ }^{* * *} p<0.001$.

\subsection{The Analysis of Moderating Effect}

This study employed multiple-group analysis to examine the moderating effects of the content types of live streaming on the conceptual model, as shown in Figure 1. The samples of this study were divided into two groups, respondents of the first group watched content that sells products $(\mathrm{n} 1=89)$, while respondents of the other group watched demonstration teaching content $(\mathrm{n} 2=105)$. This study formulated the $\chi 2$ difference test by individually constraining suitable pairs of $\beta$ estimates to ensure equivalence between the groups, which was conducted to determine whether chi-square values changed significantly in one degree of freedom $(\chi 2=3.84, \mathrm{df}=$ $1, \alpha=0.05)$ (Bagozzi and Heatherton, 1994). The $\chi 2$ difference of $(\Delta \chi 2)$ exceeded 3.84 , which indicates that the difference between the coefficients of the two groups reached the level of significance (Tsao and Chen, 2011).

Estimate coefficients and goodness-of-fit indices were adopted in the two-group comparison, as presented in Table 4. According to Table 4, for the respondent group 
that watched demonstration teaching ( $\beta$ teaching, ATW-> PI $=0.714 * * *)$, the positive impact on repurchase intention attitude toward watching was not significantly higher than the respondents group that watched selling products ( $\beta$ selling, ATW-> PI = 0.698***); therefore, H7a is not supported. In the same way, for the respondent group that watched demonstration teaching ( $\beta$ teaching, ATW-> $\mathrm{PWOM}=0.742 * * *)$, the positive impact on positive word-of-mouth was not higher than the respondent group that watched selling products ( $\beta$ selling, ATW-> PWOM $\left.=0.883^{* * *}\right)$; therefore, $\mathrm{H} 7 \mathrm{~b}$ is not supported. According to the above test results, the influence of attitude toward watching on repurchase intention and positive wordof-mouth were not affected by the content type of the live stream.

Table 4: The results of testing moderating effects of content type

\begin{tabular}{|c|c|c|c|c|c|c|c|c|c|c|}
\hline \multirow{2}{*}{\multicolumn{2}{|c|}{ Path }} & \multicolumn{2}{|c|}{$\begin{array}{l}\text { Selling product } \\
(\mathrm{n} 1=89)\end{array}$} & \multicolumn{2}{|c|}{$\begin{array}{c}\text { Demonstration teaching } \\
(\mathrm{n} 2=105)\end{array}$} & \multicolumn{2}{|c|}{$\begin{array}{c}\text { Degree of } \\
\text { freedom }\end{array}$} & \multicolumn{2}{|c|}{$\begin{array}{l}\chi^{2} \text { difference } \\
\text { test }\end{array}$} & \multirow[b]{2}{*}{ Result } \\
\hline & & $\begin{array}{c}\text { Standardized } \\
\text { coefficient }\end{array}$ & $\begin{array}{c}t \text {-value } \\
\text { (S.E.) }\end{array}$ & $\begin{array}{c}\text { Standardized } \\
\text { coefficient }\end{array}$ & $\begin{array}{c}t \text {-value } \\
\text { (S.E.) }\end{array}$ & d.f. & $\Delta$ d.f. & $\chi^{2}$ & $\left|\Delta \chi^{2}\right|$ & \\
\hline $\mathrm{H} 7 \mathrm{a}$ & $\begin{array}{c}\text { ATW -> } \\
\text { PI }\end{array}$ & $0.698 * * *$ & $\begin{array}{c}7.845 \\
(0.085)\end{array}$ & $0.714 * *$ & $\begin{array}{c}8.61 \\
(0.080)\end{array}$ & 1165 & 1 & 2322.69 & 0.028 & Unsupported \\
\hline $\mathrm{H} 7 \mathrm{~b}$ & $\begin{array}{l}\text { ATW -> } \\
\text { PWOM }\end{array}$ & $0.883 * * *$ & $\begin{array}{l}11.567 \\
(0.074)\end{array}$ & $0.742 * *$ & $\begin{array}{c}9.58 \\
(0.079)\end{array}$ & 1165 & 1 & 2323.45 & 0.792 & Unsupported \\
\hline
\end{tabular}

Goodness Fit: $\chi^{2}(194)=2323.665$; d.f. $=1164 ; \chi^{2} /$ d.f. $=1.995 ;$ CFI=0.873; RMSEA=0.072

${ }^{*} p<0.05 ;{ }^{* *} p<0.01 ;{ }^{* * *} p<0.001$.

\section{Discussion}

\subsection{Summary of Findings}

According to relevant theories, this study established the research framework and hypotheses to explore how to improve the effects of live streaming. Different from previous studies, this study further examined the change of causal path in the effect model from the perspective of the content type of live streaming. This study collected data by online questionnaire survey, and a structural equation model was employed to test the hypotheses. It is expected that the results of this study can provide more inspiration and reflection for academic and practical circles.

The causal path test revealed that the playfulness and interactivity of live streaming had significant and positive impact on attitude toward watching, as expected. In terms of playfulness, the greater the fun, pleasure, and passing of time the audiences perceive in the process of watching live streaming, the more helpful to improve their attitude toward watching. At the same time, when audiences can perceive more twoway and real-time interaction with the live stream hosts, and the hosts respond to their questions and give suggestions in a timely manner, it is more helpful it is to improve the participation and positive attitude. This finding is also supported by previous researchers (Moon and Kim, 2001; Liu, 2003). Our findings reveal that usefulness and incentives do not have impact on attitude toward watching, which 
may indicate that, under non-obligatory situations, audiences are motivated more by playfulness and interactivity.

The significant and positive impact of attitude toward watching on consumers' purchase intention and positive word-of-mouth spreading intention is also verified, as expected. The results show that when watching a live stream, the more positive the perception, better emotion, and stronger watching intention of the audiences, the more helpful to improve the consumers' purchase intention, and they are more willing to recommend the live stream websites to friends. In accordance with the opinions of other researchers, a good incentive for follow-up behavioral intention based on a good attitude has also been verified in this study of live streaming (Belch and Belch, 2004; Lee and Lee, 2011; Bitner, 1990).

However, the moderating effects were insignificant in this research and we propose, as a result, that several impacts might have caused this result. For instance, audiences may feel frustrated when they watch a video if they hear about only one product for a long time or if the speed of the video upload is slow or non-scheduled (Sykes and Zimmerman, 2014). Hence, the lengths and updating frequency of videos could be redesigned to alleviate the frustration of audiences. Furthermore, Park and Lin (2020) highlighted the importance of live content-product fit and celebrity-product fit in improving online shoppers' intentions to buy the products. Therefore, sellers should decide how to use celebrities in promoting their products and should develop relevant strategies in terms of what types of celebrity are most efficient or what types of product can be successfully advertised by celebrities.

\subsection{Managerial Implications and Contributions}

In recent years, with the thriving development of live streaming, LSPs are emerging in large numbers. Through live streaming, people can grasp the latest product information anytime and anywhere without leaving home, which has caused qualitative and quantitative changes in marketing management communication and channel strategy. Due to the live stream function of large social websites and the emergence of various LSPs, the era of nationwide live streaming has come, and with the vigorous development of online celebrities, as well as the outbreak of Covid-19, live streaming is expected to create a new economic scale.

This study found that playfulness is the most significant variable among the four success factors, which means that the operators of LSPs should make efforts to create hedonic content or shopping guidance behavior; for example, live streaming can be operated towards hedonic themes, such as music, dance, food, tourism, fitness, and cosmetics, or sellers can discuss some topics that are not directly related to the products, such as weather, current affairs, interesting things, etc., and the products could be introduced during the process of chatting.

In addition, interactivity is a significant factor to improve the performance of live streaming. 
To increase interactivity in the process of live streaming, this study suggested three aspects for consideration:

1) In terms of communication direction, managers of the LSPs can strengthen the two-way vertical communication between the hosts and the audiences by means of replying to messages from audiences members, and inviting audiences to join the live stream to increase interactivity and enhance the sense of participation.

2) In terms of communication timeliness, it is suggested that live stream hosts can reply to and interact with personalized questions in real time.

3) In terms of image technology, live streaming presents higher authenticity than ordinary audio-visual technology, as every movement will be directly transmitted to the audience, and this un-editable feature highlights the on-thespot reaction and personal charm of the live stream hosts (SHOPLINE, 2020). Therefore, improving the on-the-spot reaction ability and personal charm of the hosts enhances the interaction with the audience and makes the live content more trustworthy, and the audience comes to admire and rely more on the guidance of the shopping brand or the live stream hosts.

The results of this study show that the impact of attitude toward watching on purchase intention and positive word-of-mouth spreading intention has the same effects on the two content types of live streaming. Therefore, it is suggested that the live streaming industry should pay attention to the quality of the video content; for example, to strengthen the theme diversity and depth of the shopping guide, and enhance the effects of useful, but insignificant, factors in the model by improving the quality of the live content.

Most related research focused on the success factors, motivation, and intention, or the loyalty and intention of continuous use of live streaming, but seldom discussed the correlation between the success factors of live streaming and attitude toward watching, or examined the correlation changes based on the content types of the live streams. During the epidemic and era of increased online social communities, it is intended that this study can provide insights and thinking for popular live stream hosts to improve their business performance.

\subsection{Limitations and Directions for Further Research}

Due to the subjective and objective factors in the research process, this study has the following limitations.

1) Due to the use of an online questionnaire in this study, the respondents can only fill in the questionnaire after watching the designated video. In order to improve the representativeness of the samples, screening questions in the questionnaire were designed to exclude the respondents that did not watch the whole video: with 78 unqualified questionnaires and an unqualified rate of about $30 \%$, this study suspected that it resulted from fast forwarding or incomplete watching. Future researchers can set a function to ensure the whole video is watched 
according to requirements in the online questionnaire before the respondents can continue the process, which would reduce the invalid sample rate.

2) While there were four success factors mentioned in this research framework, only two were significant factors. As this study is based on existing literature review, other dimensions that could significantly affect the performance of live streaming cannot be highlighted.

Due to the above limitations, this study offers the following suggestions for future researchers.

1) Qualitative research can be used for exploratory research to clarify the dimensions of the success factors of the live streaming benefits.

2) This study suggests that the characteristics of live streaming hosts, such as professionalism or popularity, are important factors to explore live streaming performance. It is suggested that follow-up researchers can conduct in-depth analysis and verification of the variable types of characteristics of live stream hosts.

3) While this study only adopted the LSP of Facebook for research, other LSPs have their own characteristics, thus, differences might exist among different platforms. It is suggested that follow-up researchers can compare the causal paths of the models according to the characteristics of different platforms. It is intended that these research results can provide more reference for live streaming hosts and related operators in their strategy management in the future.

\section{References}

[1] Agba, A. A. M. and Ushie, E.M. (2010). Motivational incentives and staff turnover in the hospitality industry In Cross River State, Nigeria. Global Journal of Management and Business Research, 10(8), pp.18-28.

[2] Ajzen, I. and Fishbein, M. (1980). Understanding attitudes and predicting social behaviour. Prentice-Hall, Englewood Cliffs, New Jersey.

[3] Anderson, J. C. and Gerbing, D. W. (1988). Structural equation modeling in practice: A review and recommended two-step approach. Psychological bulletin,103(3), pp.411.

[4] Bagozzi, R. P. and Heatherton, T. F. (1994). A general approach to representing multifaceted personality constructs: Application to state selfesteem. Structural Equation Modeling, 1(1), pp.35-67.

[5] Bagozzi, R. P. and Yi, Y. (1988). On the evaluation for structural equation models. Journal of Academy Marketing Science, 16, pp.74-94.

[6] Barnett, P. (1990). Definition, design, and measurement. Play and Culture, 3, pp.319-336.

[7] Baumgartner, H. and Homburg, C. (1996). Applications of structural equation modeling in marketing and consumer research: A review. International Journal of Research in Marketing, 13, pp.139-161. 
[8] Belch, G. E. and Belch, M. A. (2004). Advertising and Promotion: An Integrated Marketing Communications Perspective, New York: NY: McGrawHill.

[9] Bitner, M. J. (1990). Evaluating service encounters: the effects of physical surroundings and employee responses. The Journal of Marketing, pp.69-82.

[10] Brooks, C. M. and Harris, K. K. (1998). Celebrity athlete endorsement: An overview of the key theoretical issues. Sport Marketing Quarterly, 7(2), pp.3444.

[11] Browne, M. W. and Cudeck, R. (1992). Alternative ways of assessing model fit. In: Bollen, K. A., \& Long, J. S. (Eds.), Testing structural equation models. Beverly Hills, CA: Sage.

[12] Bruner II, G. C. and Kumar, A. (2005). Explaining consumer acceptance of handheld Internet devices. Journal of business research, 58(5), pp.553-558.

[13] Chen, L. (2017). Be famous enough so that can be used! YouTube APP provides live streaming for sponsorship [Online]. Available from: https://udn.com/news/story/9/2272680 (Accessed: 20 July 2021).

[14] Chiang, S. (2011). A Study On Motivation, Attitude, Behaviour And Advertising Effectiveness Of Internet Video Advertising Audiences, Unpublished thesis, Department of Business Administration at the National Sun Yat-sen University.

[15] Chin, W. W. and Gopal, A. (1995). Adoption intention in GSS: relative importance of beliefs. ACM SIGMIS Database: the DATABASE for Advances in Information Systems, 26(2-3), pp.42-64.

[16] Davis, F. D. (1989). Perceived Usefulness, Perceived Ease of Use, and User Acceptance of Information Technology, MIS Quarterly, 13(3), pp.319-339.

[17] Davis, F. D. (1993). User acceptance of information technology: system characteristics, user perceptions and behavioural impacts. International journal of man-machine studies, 38(3), pp.475-487.

[18] Davis, F. D., Bagozzi, R. P. and Warshaw, P. R. (1992). Extrinsic and intrinsic motivation to use computers in the workplace. Journal of applied social psychology,22(14), pp.1111-1132.

[19] Day, G. S. (1971). Attitude change, media and word of mouth. Journal of Advertising Research, 11(6), 31-40.

[20] Demirci, U. B. and Miele, P. (2009). Sodium borohydride versus ammonia borane, in hydrogen storage and direct fuel cell applications. Energy \& Environmental Science, 2(6), pp.627-637.

[21] Dhameja, S. K. and Dhameja, S. (2009). Industrial psychology. New Delhi. S.K Kataria and sons.

[22] Fishbein, M. and Ajzen, I. (1975). Belief, attitude, intention, and behavior: An introduction to theory and research. Addison-Wesley, London, England.

[23] Fornell, C. (1992). A national customer satisfaction barometer: the Swedish experience. Journal of Marketing, 56(1), pp.6-21. 
[24] Fornell, C. and Larcker, D. F. (1981). Structural equation models with unobservable variables and measurement error: Algebra and statistics. Journal of marketing research, pp.382-388.

[25] Hair, J. F., Black, W. C., Babin, B. J., Anderson, R. E. and Tatham, R. L. (2009). Análise multivariada de dados. Bookman Editora.

[26] Harrison-Walker, L. J. (2001). The measurement of word-of-mouth Communication and an investigation of service quality and customer commitment as potential antecedents. Journal of Service Research, 4(1), pp.60-75.

[27] Hsu, A. (2001), A Study of Interactive Functions in Taiwan Digital Libraries Evaluation and Users' Needs Analysis, Institute of Communication Studies at the National Chiao Tung University.

[28] Hsu, C. L. and Lin, J. C. C. (2008). Acceptance of blog usage: The roles of technology acceptance, social influence and knowledge sharing motivation. Information \& management, 45(1), pp.65-74.

[29] Huang, Y. (2009). An analysis of technology acceptances of class blogs in teacher-student interactions. Journal of Network Society, 79. [Online]. Available from: https://www.nhu.edu.tw/ society/e-j/79/79-03.htm (Accessed: 20 July 2021).

[30] InsightXplorer Ltd (2017). What live broadcasts do Taiwanese netizens watch? [Online]. Available from: https://www.ixresearch.com/news/news_07_06_17 (Accessed: 20 July 2021).

[31] Jeffries, L. (2011). The revolution will be so cute: YouTube "hauls" and the voice of young female consumers. Studies in popular culture, 33 (2), pp.59-75.

[32] Kamins, M. A. (1990). An investigation into the "match-up" hypothesis in celebrity advertising: When beauty may be only skin deep. Journal of advertising, 19(1), pp.4-13.

[33] Karahanna, E. and Straub, D. W. (1999). The psychological origins of perceived usefulness and ease-of-use. Information \& management, 35(4), pp.237-250.

[34] Keller, L. K. and Swaminathan, V. (2020). Strategic Brand Management: Building, Measuring, and Managing Brand Equity, Global Edition, 5th Edition Person Education Limited.

[35] Lai, M. and Chang, C. (2016), Exploring Usage Behaviors of Webcast Video Platform: From Awareness to Adoption. Journal of National Taichung University of Science and Technology,3(1), pp31-47

[36] Lee, J., and Lee, M. (2011). Factors Influencing the Intention to Watch Online Video Advertising. Cyberpsychology, Behavior \& Social Networking, 14(10), pp.619-624.

[37] Liu, Y. (2003). Developing a scale to measure the interactivity of websites. Journal of advertising research, 43(2), pp.207-216.

[38] Locke, E. A. and Latham, G. P. (1990). A theory of goal setting \& task performance. Prentice-Hall, Inc. 
[39] McMillan, S. J. and Hwang, J. S. (2002). Measures of perceived interactivity: An exploration of the role of direction of communication, user control, and time in shaping perceptions of interactivity. Journal of Advertising, 31(3), pp.29-42.

[40] MIC. (2017). Netizens love Facebook, YouTube, and 17 live broadcasts very much. [Online]. Available from:

https://mic.iii.org.tw/IndustryObservations_PressRelease02.aspx?sqno=475 (Accessed: 20 July 2021).

[41] Molinari, L. K., Abratt, R. and Dion, P. (2008). Satisfaction, quality and value and effects on repurchase and positive word-of-mouth behavioral intentions in a B2B services context. Journal of Services Marketing, 22(5), pp.363-373.

[42] Moon, J. W., and Kim, Y. G. (2001). Extending the TAM for a World-WideWeb context. Information \& management, 38(4), pp.217-230.

[43] Mooney, A., and Johnsmeyer, B. (2015). I-want-to-buy moments: How mobile has reshaped the purchase journey. pp.2-6.

[44] Nunnally, J. (1978). Psychometric methods. New York: McGraw-Hill.

[45] Ou, C. (2009). A study of MOODLE users combine web 2.0 instructional technology, unpublished thesis, Department of Recreation and Leisure Industry Management at the National Taiwan Sport University.

[46] Park, Hyun Jung and Lin, Li Min. (2020). The effects of match-ups on the consumer attitudes toward internet celebrities and their live streaming contents in the context of product endorsement. Journal of Retailing and Consumer Services, Elsevier, vol.52(C).

[47] Pelet, J. É., Ettis, S., and Cowart, K. (2017). Optimal experience of flow enhanced by telepresence: Evidence from social media use. Information \& Management, 54(1), pp.115-128.

[48] Peterson, R. A., \& Kerin, R. A. (1977). The female role in advertisements: Some experimental evidence. The Journal of Marketing, 41(4), pp.59-63.

[49] Schmitt, B. H. (1999). Experiential Marketing: How to Get Customer to Sense, Feel, Think, Act, and Relate to Your Company and Brands, New York, NY: The Free Press.

[50] Shih, T. and Yang, L. (2011). A Study of Promotion Strategies for Mobile Advertising, Lunghwa University of Science and Technology

[51] Shih, H. P. (2004). An empirical study on predicting user acceptance of eshopping on the Web. Information \& Management, 41(3), pp.351-368.

[52] Shopline (2020). Which live broadcast platform is the most popular? An evaluation and analysis of six major live broadcast platforms, let you understand what live streaming is popular. [Online]. Available from: https://blog.shopline.tw/6-live-platform-compare/ (Accessed: 20 July 2021).

[53] Steuer, J. (1992). Defining Virtual Reality: Dimensions Determining Telepresence. Journal of Communication, 42, pp.73-93.

[54] Sykes, S. and Zimmerman, J. (2014). Making sense of haul videos: Selfcreated celebrities fill a fashion media gap. In CHI '14 Extended Abstracts on 
Human Factors in Computing Systems (p. 2011-2016). New York, NY: Association for Computing Machinery.

[55] Taylor, S. and Todd, P. A. (1995). Understanding information technology usage: A test of competing models. Information systems research,6(2), pp.144176.

[56] Tsao, W. and Shao, Y. (2018). How Is Flow Induced? From the Perspective of Online and Offline Channels, International Journal of Marketing Studies, 10(1), pp. 11-28.

[57] Tsao, W. and Mau, T. (2019). Ethics in social media marketing: How should sponsorship information be disclosed in online product reviews?, Aslib Journal of Information Management, 7(2), pp. 195-216.

[58] Tsao, W. and Yang, F. (2017). "Factors that Influence the Intention to Use Mobile Shopping Platforms Which Feature Virtual Shelves and QR Codes Based on TAM", International Review of Management and Business Research, 6(2), pp.758-776.

[59] Tsao, W. and Chen, Y. (2011). A study of the impact and application of causecorporate brand alliance on Taiwan tourist amusement industry. African Journal of Business Management, 5(2), 316-331.

[60] TWNIC. (2020). Taiwan Internet Report. [Online]. Available from: https://report.twnic.tw/2020/ (Accessed: 20 July 2021).

[61] Wang, C. (2016). A Study of Twitch TV Fans Continuous Use of Video Games Live Broadcast: Uses and Gratifications Theory, Unpublished thesis, Department of Information and Communication at the Southern Taiwan University of Science and Technology.

[62] Wang, H. (2016). A study of elementary films' demonstration teaching concerning cultivating self-care skills of children with autism: Taking hand washing as an example. Bulletin of Special Education. 1, 33-62.

[63] Wendy (2016). What are the Internet celebrities broadcasting? Five main points of Facebook live streaming. [Online]. Available from: https://www.gemarketing.com.tw/article/ (Accessed: 20 July 2021)

[64] Wirtz, J., \& Chew, P. (2002). The effects of incentives, deal proneness, satisfaction and tie strength on word-of-mouth behaviour. International journal of service industry management, 13(2), 141-162.

[65] Yang, Y. (2014). The Factors Influencing on Behavioral Intention of Mobile Shopping Virtual Shelves applying QR Code - Based on TAM, Unpublished thesis, Department of Business Administration at the National Chin-Yi University of Technology. 
Appendix A. Measurement Instruments

This appendix contains the statements used in the survey. Respondents were asked to what degree they agree or disagree with these statements on a seven-point Likert scale.

\section{Usefulness (adapted from Davis, 1989, $\alpha=.954$ )}

I believe watching a live stream....

UFN1 ..... will be helpful for me to know the performance of the products.

UFN2 ..... will be helpful for me to know the product information more efficiently.

UFN3 In comparison with other methods, .... will be easier for me to know product information.

UFN4 ..... will make understanding product information easier.

UFN5 In general, ... is useful for shopping.

Playfulness (adapted from Moon and Kim, 2001, $\alpha=.894$ )

When watching live streaming, ...

PFN1 ..... I fail to realize the passing of time.

PFN2 ..... I often forget what I need to do.

PFN3 $\quad \ldots .$. it brings me a lot of pleasure.

PFN4 …. it keeps me happy.

PFN5 … it inspires my imagination.

Interactivity (adapted from Liu, 2003, $\alpha=.947$ )

When watching a live stream, I believe that...

ITA1 ..... there is a two-way communication between the audience and the host.

ITA2 ..... the host can effectively collect the response of every audience member.

ITA3 $\ldots$. the host provides the opportunity for real-time responses and reflections.

ITA4 .... live streaming is helpful for real-time communication.

ITA5 .... it is possible to communicate with many people at the same time.

ITA6 .... the host can respond and deal with the questions or suggestions of the audience in real time.

Incentive (adapted from Locke and Latha, 1990, $\alpha=.949$ )

ICT1 I will watch a live stream for the relevant information content of a special offer.

ICT2 I will watch a live stream for activities content of value for money.

ICT3 I will watch a live stream for activities content of saving money.

ICT4 I will watch a live stream for activities content of offering gifts.

ICT5 If I am hoping to get information of a relevant special offer, I would like to watch this live stream.

Attitude toward watching (adapted from Lee and Lee, 2011, $\alpha=.966$ ).

ATW1 I like watching live streaming.

ATW2 I feel happy when watching live streaming.

ATW3 I think watching live streaming is valuable.

ATW4 I hold a positive attitude toward watching live streaming. 


\begin{tabular}{|c|c|}
\hline ATW5 & I will watch live streaming very carefully. \\
\hline ATW6 & I will watch a live stream more than once. \\
\hline ATW7 & I am very interested in live streaming. \\
\hline Purchase & intention (adapted from Belch and Belch, 2004, $\alpha=.954$ ). \\
\hline PI1 & I want to buy the goods introduced by live streaming. \\
\hline $\mathrm{PI} 2$ & The goods introduced by live streaming attract me to consume. \\
\hline $\begin{array}{l}\text { PI3 } \\
\text { bit higher }\end{array}$ & I am willing to consume even if the goods price of the live stream is a little \\
\hline PI4 & I will consume based on the information introduced by the live stream. \\
\hline PI5 & I will purchase the goods verified by the live stream. \\
\hline Positive I & Word-of-Mouth (adapted from Molinari et al., 2008, $\alpha=.964)$ \\
\hline PWOM1 & I will recommend others to watch live streaming. \\
\hline PWOM2 & I will encourage others to watch live streaming. \\
\hline PWOM3 & I will mention something favourable about live s \\
\hline
\end{tabular}

